\title{
A Retrospective Review of Radiographic and Clinical Findings from the M6 Cervical Prosthesis
}

\author{
İsmail Oltulu ${ }^{1}$, Özgür Korkmaz ${ }^{2}$, Ender Sarıŏlu ${ }^{3}$, Mehmet Aydoğan ${ }^{4}$ \\ ${ }^{1}$ Department of Orthopedics and Traumatology, Emsey Hospital, Istanbul, Turkey \\ ${ }^{2}$ Department of Orthopedics and Traumatology, Medicalpark Pendik Hospital, İstanbul, Turkey \\ ${ }^{3}$ Department of Orthopedics and Traumatology, Medicalpark Göztepe Hospital, İstanbul, Turkey \\ ${ }^{4}$ Fulya Orthopedics and Spine Center, İstanbul, Turkey
}

\section{Study Design: Retrospective clinical study.}

Purpose: To evaluate clinical results of the M6 cervical prosthesis.

Overview of Literature: Cervical disk prostheses have been developed to preserve motion and reduce degeneration in adjacent segments in degenerative disk diseases.

Methods: A retrospective evaluation was performed on 43 patients who received the M6 cervical disk prosthesis between 2012 and 2016. Standard and dynamic radiographs, computed tomography, and magnetic resonance imaging were used to evaluate all the patients preoperatively and postoperatively. The Neck Disability Index (NDI) and Visual Analog Scale (VAS) scores were examined in evaluating the clinical and functional results of patients with collapsed disk herniation who had received the M6 cervical prosthesis and to evaluate whether the core structure of the prosthesis protects motion.

Results: The mean follow-up period was $34.12 \pm 6.70$ months. Radiologically, the preoperative cervical segment ROM was measured as a mean of $5.77^{\circ} \pm 2.19^{\circ}$ preoperatively and $8.49^{\circ} \pm 2.37^{\circ}$ at the inal postoperative follow-up examination. In the patients with a preoperative disk height of $<4 \mathrm{~mm}$, the segmental ROM increased from $4.53^{\circ} \pm 2.79^{\circ}$ preoperatively to $7.2^{\circ} \pm 3.18^{\circ}$ postoperatively. In the patients with a preoperative disk height of $>4 \mathrm{~mm}$, the cervical segment ROM increased from $6.4^{\circ} \pm 1.45^{\circ}$ preoperatively to $8.6^{\circ} \pm 2.02^{\circ}$ at the inal postoperative follow-up examination. The NDI scores reduced from $53.86 \pm 9.77$ preoperatively to $22.69 \pm 7.26$ postoperatively and the VAS scores reduced from $8.74 \pm 0.58$ to $1.88 \pm 1$.14. During follow-up in any patient, no collapse of the levels at which surgery was performed was observed. No heterotopic ossiication or implant failure was recorded in any patient during the follow-up period.

Conclusions: The M6 new-generation cervical disk prosthesis had few complications. No heterotopic ossiication was observed in any patient, and lexion-extension ROM was maintained in all the patients, indicating the M6 prosthesis as a promising alternative.

Keywords: Cervical; Prosthesis; Disc

\section{Introduction}

Cervical disk prostheses have been developed to preserve motion and reduce degeneration in adjacent segments in degenerative disk diseases as an alternative to anterior cervical discectomy and fusion (ACDF), considered the gold

Received Dec 31, 2018; Revised Feb 24, 2019; Accepted Mar 26, 2019

Corresponding author: İsmail Oltulu

Department of Orthopedics and Traumatology, Emsey Hospital, Çamlık Mah. Selçuklu cad. No:22 Pendik, İstanbul, Turkey

Tel: +90-444-25-99, Fax: +90-216-646-0096, E-mail: ioltulu@hotmail.com 
standard treatment [1]. An increase in intradiscal pressure causes excessive motion in an adjacent segment following single level fusion $[2,3]$. This causes the degeneration of the adjacent segment requiring further surgery [4]. In addition to adjacent segment degeneration, complications have been reported, including graft migration, non-union, and kyphotic malunion [5].

Cervical artificial disk prosthesis can be used with the aim of restoring and maintaining the mobility and function of the affected cervical level [6]. There has been a significant increase in the last decade in the number of different artificial disk replacement devices, and all of the largest manufacturers have at least one design of spinal implant on the market.

New-generation prostheses have been produced with the aim of mimicking normal biomechanics, whereas the production of the classic ball-and-socket type prostheses have started to decline. An example of the new prosthesis being developed is the M6 cervical disk prosthesis (Spinal Kinetics, Sunnyvale, CA, USA). It has a compressible central core, allowing for free motion in six directions [7]. The compressible polymer core mimics the hardness and function of the normal disk. The polyethylene ring is designed to mimic the annulus, and the polymer layer covers the core and fiber layer, preventing the growth of soft tissues and catching possible debris (Fig. 1A, B).

The aim of this study was to present the mid-term results obtained from 43 patients treated with a biomimetic cervical disk prosthesis, through clinical and radiological analysis, to evaluate complications frequently encountered, and report on the mid-term results regarding prosthesis survival.

\section{Materials and Methods}

The study protocol was approved by the Institutional Review Board of Marmara University Health Science İnstitue (protocol no., 2018-174). Informed constent form was taken from all patient that were included in the study. Retrospective evaluation was performed of 48 patients who received the M6 cervical disk prosthesis between 2012 and 2016. The inclusion criteria for the study were treatment with cervical disk prosthesis of patients aged $>18$ years, with single level cervical discopathy and findings of radiculopathy or myelopathy, who were unresponsive to 6 weeks of medical treatment.

The exclusion criteria were defined as kyphotic deformi-

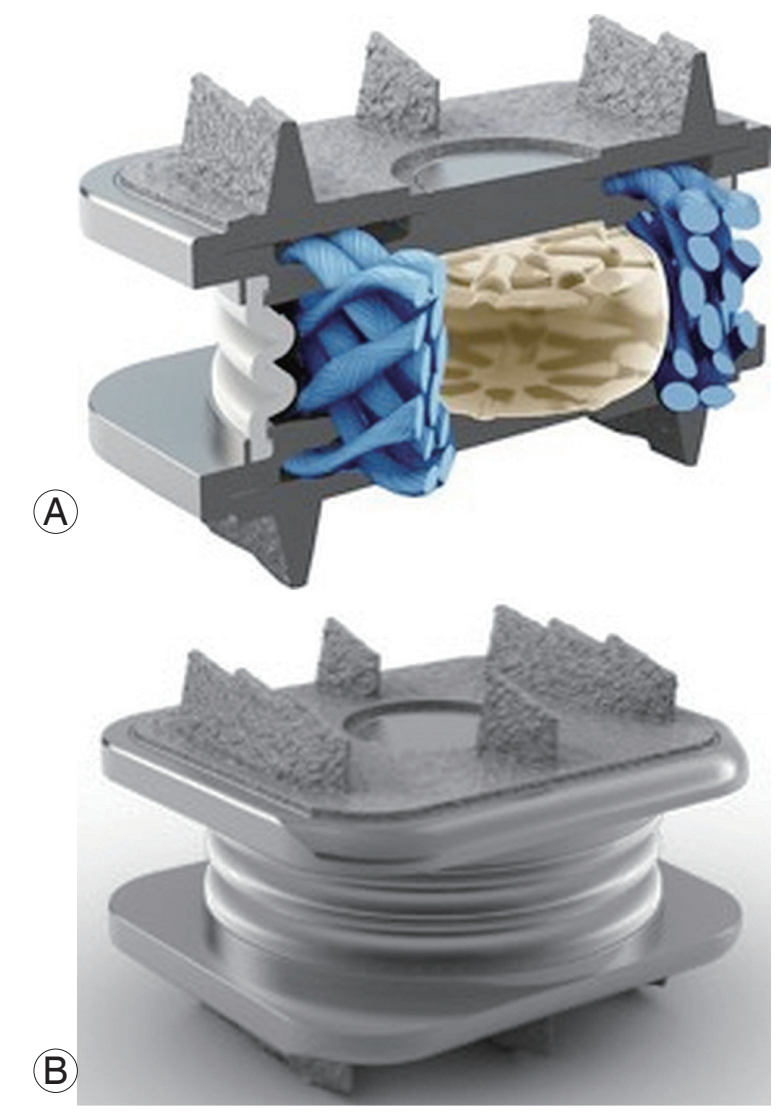

Fig. 1. (A) Core structure of the prosthesis. (B) External structure and general appearance of the prosthesis.

ty, posterior longitudinal ligament ossification, pregnancy, facet joint arthrosis, trauma or instability, advanced osteoporosis, and inflammatory diseases such as rheumatoid arthritis, diffuse idiopathic hyperosteosis syndrome, and ankylosing spondylitis. Owing to the exclusion criteria, five patients were excluded from the study.

The prosthesis was applied at the C5-6 level in $25 \mathrm{pa}-$ tients, at the C6-7 level in 13 patients and at the C4-5 level in five patients.

\section{Surgical procedure}

The patients were positioned supine under general anesthesia. Surgical exposure was established with a transverse incision from the contralateral side. Over-dissection of the ligamentum coli was avoided. A first Caspar retractor was placed in the mediolateral plane in parallel with the anterior background when the surgical level was determined (Fig. 2A, B). All anatomical structures causing compression were removed, including the posterior longitudinal ligament and uncinate process. Following the completion 
of decompression, the appropriate prosthesis size and central location of the prosthesis was determined under fluoroscopy control and then implanted (Fig. 2C-F). It was preferable that the prosthesis completely covered the endplate on the foreground and that the prosthesis covers the anterior bone boundary. A soft neck collar was applied for 1 week postoperatively. Heterotopic ossification prophylaxis of $15 \mathrm{mg}$ meloxicam per day was administered for 3 weeks.

\section{Radiological and clinical evaluation}

All the patients were evaluated preoperatively with standard and dynamic radiographs, computed tomography, and magnetic resonance imaging, and postoperatively with standard and dynamic radiographs. The range of motion (ROM) and segmental lordosis angles were measured radiologically (Fig. 3). The Neck Disability Index (NDI) and Visual Analog Scale (VAS) scores were examined for the evaluation of the clinical and functional results.

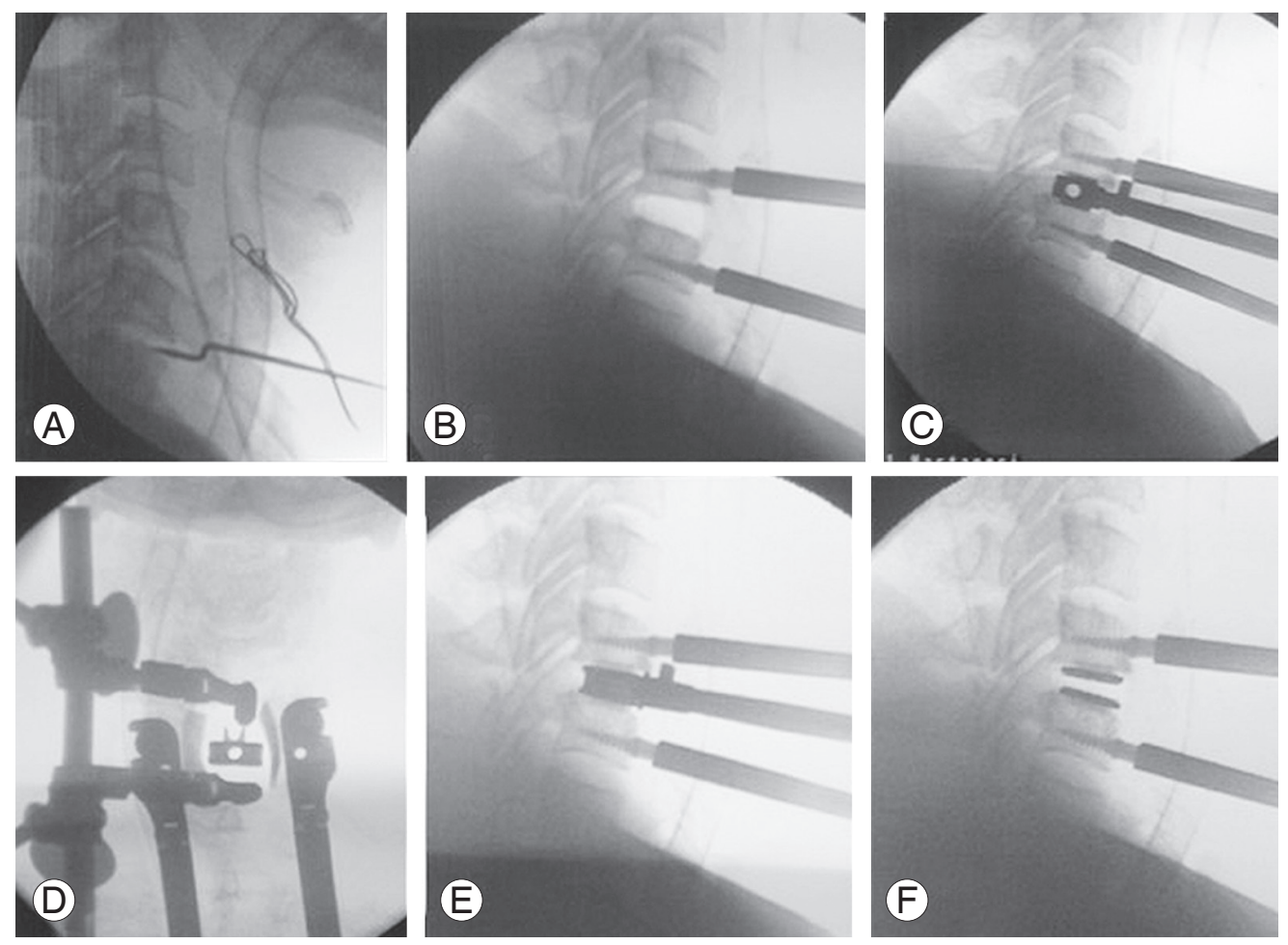

Fig. 2. (A) Determination of the surgical level. (B) Placing of Caspar retractor and checking with scopy. (C) Placing of the trial prosthesis and control of the placement in the anteroposterior plan with scopy. (D) Control of the placement of the trial prosthesis in the mediolateral plan with scopy. (E) Appropriate size prosthesis placement. (F) Final position of the prosthesis following placement in the anteroposterior plane.
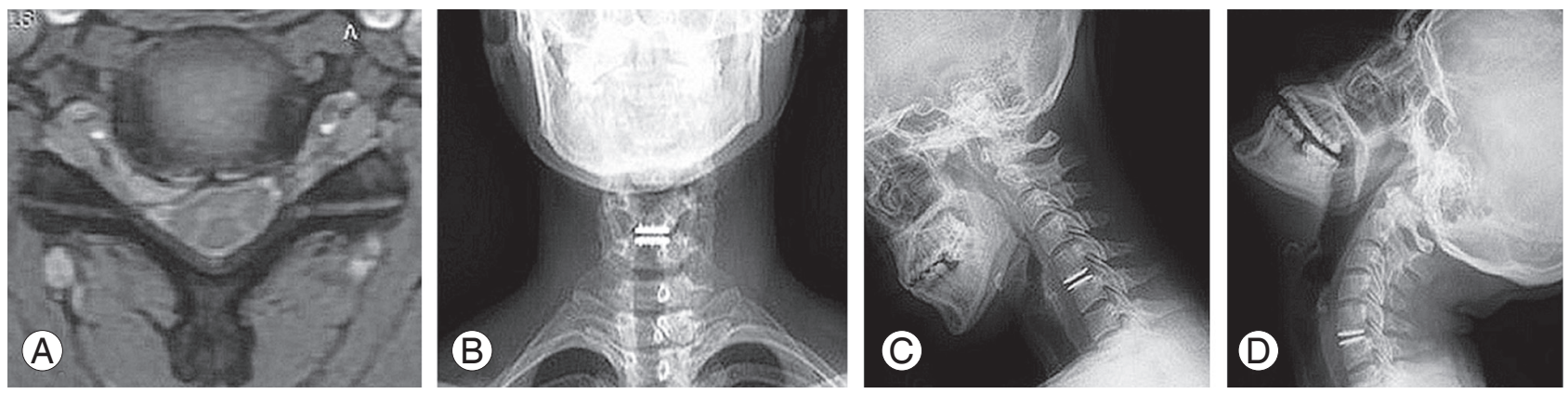

Fig. 3. (A) Preoperative axial magnetic resonance imaging C5-C6 disk hernia. (B) Postoperative anteroposterior X-ray. (C) Postoperative lateral flexion X-ray. (D) Postoperative lateral extension X-ray. 
The patients were separated into two groups according to preoperative disk heights of $<4 \mathrm{~mm}(\mathrm{n}=15)$ and $>4 \mathrm{~mm}$ $(\mathrm{n}=28)$, respectively, and the effect of disk height on ROM was investigated.

\section{Statistical analysis}

NCSS software 2007 (NCSS Statistical Software, Kaysville, UT, USA) was used to perform statistical analyses. Descriptive statistical methods (mean, standard deviation, median, frequency, percentage, minimum, and maximum) were used when evaluating the study data. Repeated measures variance analysis was used to evaluate variables showing normal distribution and, in paired comparisons, the Bonferroni test was used. In the evaluation of variables not showing normal distribution, the Friedman test was applied; in paired comparisons, the Wilcoxon signed ranks test was used. A value of $p<0.05$ was accepted as statistically significant.

\section{Results}

The mean age of the patients was $42.46 \pm 5.92$ years and the mean follow-up period was $34.12 \pm 6.70$ months. Radiologically, the preoperative cervical segment ROM was measured as a mean of $5.77^{\circ} \pm 2.19^{\circ}$ preoperatively and $8.49^{\circ} \pm 2.37^{\circ}$ at the final postoperative follow-up examination. In patients with a preoperative disk height of $<4 \mathrm{~mm}$, the segmental ROM increased from $4.53^{\circ} \pm 2.79^{\circ}$ preoperatively to $7.2^{\circ} \pm 3.18^{\circ}$ postoperatively. In the patients with a preoperative disk height of $>4 \mathrm{~mm}$, the cervical segment ROM increased from $6.4^{\circ} \pm 1.45^{\circ}$ preoperatively to $8.6^{\circ} \pm 2.02^{\circ}$ at the final postoperative follow-up examination. No statistically significant difference was determined in either group with respect to the change in cervical segment ROM ( $p>0.05)$.

A statistically significant increase was observed in the segmental lordosis angle from $1.98^{\circ} \pm 2.32^{\circ}$ preoperatively to $5.3^{\circ} \pm 2.17^{\circ}$ at the final postoperative follow-up $(p<0.05)$. Anterior disk height in the surgical site increased from $4.36 \pm 0.99 \mathrm{~mm}$ to $6.33 \pm 0.96 \mathrm{~mm}$ and this difference was determined to be statistically significant $(p<0.05)$. The posterior disk height increased from $4.11 \pm 1.02 \mathrm{~mm}$ to $6.05 \pm 1.04 \mathrm{~mm}$ and this difference was determined to be statistically significant $(p<0.05)$. The NDI scores reduced from $53.86 \pm 9.77$ preoperatively to $22.69 \pm 7.26$ postoperatively and the VAS scores reduced from $8.74 \pm 0.58$ to $1.88 \pm 1.14$; these differences were determined to be statistically significant $(p<0.05)$. No adjacent segment disease was observed in any patient. No collapse was observed during follow-up of the levels at which surgery was performed in any patient. No heterotopic ossification or implant failure was observed in any patient during the follow-up period.

Complications were as follows: dysphagia was reported in three patients (15\%) and dysphonia in two patients $(10 \%)$ in the postoperative period. The symptoms in all the five patients recovered in 1 week with medical treatment.

\section{Discussion}

Cervical disk prostheses were introduced to eliminate the complications that can develop as a result of fusion. Over a short period, several different designs of cervical disk prosthesis began to be used for this purpose. Of the cervical prostheses recently developed to mimic the normal biomechanical structure, the M6 cervical disk prosthesis has started to be widely used. Its short-term results have been particularly promising. Compared with other prostheses, the M6 prosthesis has advantages in axial rotation, translation, and lateral bending motions in addition to flexion and extension motions. While this mimics the biomechanics better theoretically, the body of the prosthesis is also considered to mimic the cervical disk better biomechanically. Despite the theoretical consideration that there is an increase in ROM in all the planes, this has not been shown in clinical studies yet $[7,8]$.

Although heterotopic ossification was first defined following total hip arthroplasty procedures, its occurrence has started to be observed frequently following cervical disk prosthesis surgery. Despite high rates of heterotopic ossification reported in the literature, risk factors, such as those in total hip arthroplasty, have not been well-defined. Heterotopic ossification has been reported at rates of $10.3 \%$ and $15 \%$ following surgical intervention with ProDesk C and Bryan cervical prostheses, respectively [911]. Yi et al. [12,13] stated that heterotopic ossification may be associated with the type of prosthesis, and reported rates of $21.0 \%$ for the Bryan disk prosthesis, $52.5 \%$ for the Mobi-C prosthesis and 71.4\% for the ProDisc C prosthesis. In the present study, no heterotopic ossification was observed, which can be attributed to not over-dissecting the longus colli as far as the lateral during surgery, careful- 
ly minimizing bleeding within the bone using bone wax, and the administration of meloxicam prophylaxis in the postoperative period. Prosthesis design can be considered important in the formation of heterotopic ossification, and the flush placement of the prosthesis to the posterior without leaving an open space is considered to reduce the risk of heterotopic ossification. However, there is a need for further, prospective randomized studies to be explain the association with prosthesis type.

Cervical disk prostheses were developed as an alternative to ACDF in cervical degenerative diseases. Although similar results are obtained neurologically and in terms of pain relief, motion is preserved with the use of a cervical disk prosthesis. Furthermore, it was reported in a recent study that recurrent radicular symptoms developed secondary to adjacent segment degeneration during longterm follow-up in $25 \%$ of patients treated with ACDF [14]. In a prospective, randomized, multicenter study by Mummaneni et al. [15], comparisons were made of a 276-patient cervical disk replacement (CDR) group treated with the prestige ST prosthesis and 265 patients treated with ACDF. Over a 2-year follow-up period, $80 \%$ of the CDR group and $75 \%$ of the ACDF group were contacted and evaluated. Although not at a clinically significant level, the results of the CDR group were improved. A statistically significant difference was observed in the rates of adjacent segment degeneration associated with the surgery, with $1.1 \%$ reported in the CDR group and 3.4\% in the ACDF group [15]. Although there was no control group treated with $\mathrm{ACDF}$ in the present study, no adjacent segment problems were observed during the follow-up in any patient treated with a cervical disk prosthesis.

In a 4-year follow-up period of patients treated with a Sasso Bryan disk prosthesis, 79\% success was reported in terms of NDI scores [16], and in a 7-year follow-up of patients treated with the Burkus Prestige Disk, 83.4\% success was reported in terms of NDI scores [17]. Dejaegher et al. [18] reported the 10-year follow-up results of patients treated with the Bryan cervical disk prosthesis as neurological recovery in $89 \%$ of patients, and significant improvement in NDI, MCS and PCS scores compared with the baseline values. In the present study, the NDI scores improved from $53.86 \pm 9.77$ preoperatively to $22.69 \pm 7.26$ postoperatively, and the VAS scores reduced from $8.74 \pm 0.58$ to $1.88 \pm 1.14$. These results were consistent with the findings in the previous literature.

In a human cadaver study by Patwardhan et al. [7], a greater increase was determined in flexion and extension compared with pre-implantation, and reductions in lateral bending and axial rotation were observed. However, it was stated this may be different in an in vivo environment [7]. Bogduk and Mercer [19] determined a significant increase in mean flexion and extension movements compared with preoperative values, with the segmental lordosis angle increasing from $1.98^{\circ}$ to $5.3^{\circ}$. In another study by Anderson et al. [1], a $4^{\circ}$ increase was reported in the adjacent segment of both the ACDF group and the prostheses group. Dejaegher et al. [18] reported that the mean ROM was $>7^{\circ}$ in patients treated with a cervical disk prosthesis, and mobility in the prosthesis was maintained in $80 \%$ of patients following a 10-year follow-up period. In the present study, cervical segment ROM was determined to have increased from $5.77^{\circ} \pm 2.19^{\circ}$ to $8.49^{\circ} \pm 2.37^{\circ}$ and the segmental lordosis angle increased from $1.98^{\circ} \pm 2.32^{\circ}$ to $5.3^{\circ} \pm 2.17^{\circ}$.

In addition to the design of the prosthesis, the surgical technique affects ROM. Over-distraction of the disk gap, protection of the anterolateral annulus and/or posterior longitudinal ligament, protection of the uncinate process, and leaving osteophytes can cause restriction in motion [20]. In the present study, full decompression was applied to all the patients. The anterolateral annulus and the posterior longitudinal ligament were excised, and overdistraction was avoided. No patient had any complaints of restricted motion in the postoperative period. The increase in ROM observed in the postoperative period can be considered to be associated with the surgical technique used. However, a limitation of the study is, with the exception of flexion and extension radiographs, no radiological studies were performed to measure lateral bending and axial rotation.

The association between preoperative and postoperative disk height and ROM has not been clarified fully. In a study by Peng et al. [21], patients were treated with ProDisc C, and improvement in ROM was greater following CDR in patients with $<4 \mathrm{~mm}$ disc collapse preoperatively, with the optimal postoperative disc height reported to be 5-7 mm. These criteria were applied to the present study and, in the 15 patients with a preoperative disc height of $<4 \mathrm{~mm}$, ROM increased from $4.46^{\circ}$ to $7.13^{\circ}$. In the 28 patients with a preoperative disc height of $>4 \mathrm{~mm}, \mathrm{ROM}$ increased from $6.37^{\circ}$ to $8.59^{\circ}$. Although a greater ROM increase was determined in patients with a preoperative disc height of $<4 \mathrm{~mm}$, no statistically significant difference was determined between the two groups ( $p>0.05$ ). 
The complications reported by Thomas et al. [8] in a study of 35 patients treated with the M6 prosthesis included subsidence in two patients, aseptic loosening in one patient, heterotopic ossification in one patient, and neurological deficit associated with hematoma developing 24 hours postoperatively in one patient, in addition to dysphagia or dysphonia lasting $>4$ weeks in three patients. In the present study, complications in the postoperative period were that of dysphagia in three patients (15\%) and voice restriction in two patients $(10 \%)$; the symptoms in all the five patients recovered in 1 week with medical treatment.

The low number of patients and the absence of a comparative group were major limitations of the present study. Therefore, there is a need for further randomized, prospective studies. Another limitation was, although motion of the prosthesis in all planes has been claimed, no lateral bending radiographs of the patients were taken and no preoperative clinical measurements were made of lateral bending or axial rotation. Although it is difficult to take correct in vivo measurements in the mediolateral plane and the axial plane, future studies should be conducted in a way that these lateral bending and axial rotation motions can be evaluated.

\section{Conclusions}

ACDF is often applied in current cervical radiculopathy and myelopathy surgery and is the currently the accepted gold standard treatment. Cervical disc prostheses applied with appropriate indications have certain advantages over ACDF in the long term. The M6 new-generation cervical disc prosthesis mimics the cervical motion unit with motion in six planes. From the results of the present study and previous data in the literature, the fact that there are few complications in the mid-term, no heterotopic ossfication was present in any patient in the present study, and flexion-extension ROM was maintained in all the patients, make the M6 prosthesis a promising alternative to ACDF.

\section{Conflict of Interest}

No potential conflict of interest relevant to this article was reported.

\section{References}

1. Anderson PA, Sasso RC, Riew KD. Update on cervical artificial disk replacement. Instr Course Lect 2007;56:237-45.

2. Fuller DA, Kirkpatrick JS, Emery SE, Wilber RG, Davy DT. A kinematic study of the cervical spine before and after segmental arthrodesis. Spine (Phila Pa 1976) 1998;23:1649-56.

3. Eck JC, Humphreys SC, Lim TH, et al. Biomechanical study on the effect of cervical spine fusion on adjacent-level intradiscal pressure and segmental motion. Spine (Phila Pa 1976) 2002;27:2431-4.

4. Goffin J, Geusens E, Vantomme N, et al. Long-term follow-up after interbody fusion of the cervical spine. J Spinal Disord Tech 2004;17:79-85.

5. Aebi M, Zuber K, Marchesi D. Treatment of cervical spine injuries with anterior plating: indications, techniques, and results. Spine (Phila Pa 1976) 1991;16:S38-45.

6. Yoon DH, Yi S, Shin HC, Kim KN, Kim SH. Clinical and radiological results following cervical arthroplasty. Acta Neurochir (Wien) 2006;148:943-50.

7. Patwardhan AG, Tzermiadianos MN, Tsitsopoulos PP, et al. Primary and coupled motions after cervical total disc replacement using a compressible six-degree-of-freedom prosthesis. Eur Spine J 2012;21:S618-29.

8. Thomas S, Willems K, van den Daelen L, Linden P, Ciocci MC, Bocher P. The M6-C cervical disk prosthesis: first clinical experience in 33 patients. Clin Spine Surg 2016;29:E182-7.

9. McAfee PC, Cunningham BW, Devine J, Williams E, Yu-Yahiro J. Classification of heterotopic ossification (HO) in artificial disk replacement. J Spinal Disord Tech 2003;16:384-9.

10. Mehren C, Suchomel P, Grochulla F, et al. Heterotopic ossification in total cervical artificial disc replacement. Spine (Phila Pa 1976) 2006;31:2802-6.

11. Ryu KS, Park CK, Jun SC, Huh HY. Radiological changes of the operated and adjacent segments following cervical arthroplasty after a minimum 24-month follow-up: comparison between the Bryan and Prodisc-C devices. J Neurosurg Spine 2010;13:299-307.

12. Yi S, Kim KN, Yang MS, et al. Difference in occurrence of heterotopic ossification according to pros- 
thesis type in the cervical artificial disc replacement. Spine (Phila Pa 1976) 2010;35:1556-61.

13. Yi S, Shin DA, Kim KN, et al. The predisposing factors for the heterotopic ossification after cervical artificial disc replacement. Spine J 2013;13:1048-54.

14. Heller JG, Sasso RC, Papadopoulos SM, et al. Comparison of BRYAN cervical disc arthroplasty with anterior cervical decompression and fusion: clinical and radiographic results of a randomized, controlled, clinical trial. Spine (Phila Pa 1976) 2009;34:101-7.

15. Mummaneni PV, Burkus JK, Haid RW, Traynelis VC, Zdeblick TA. Clinical and radiographic analysis of cervical disc arthroplasty compared with allograft fusion: a randomized controlled clinical trial. J Neurosurg Spine 2007;6:198-209.

16. Sasso RC, Anderson PA, Riew KD, Heller JG. Results of cervical arthroplasty compared with anterior discectomy and fusion: four-year clinical outcomes in a prospective, randomized controlled trial. Orthope$\operatorname{dics} 2011 ; 34: 889$.
17. Burkus JK, Traynelis VC, Haid RW Jr, Mummaneni PV. Clinical and radiographic analysis of an artificial cervical disc: 7-year follow-up from the Prestige prospective randomized controlled clinical trial: clinical article. J Neurosurg Spine 2014;21:516-28.

18. Dejaegher J, Walraevens J, van Loon J, van Calenbergh F, Demaerel P, Goffin J. 10-year follow-up after implantation of the Bryan Cervical Disc Prosthesis. Eur Spine J 2017;26:1191-8.

19. Bogduk N, Mercer S. Biomechanics of the cervical spine: I. normal kinematics. Clin Biomech (Bristol, Avon) 2000;15:633-48.

20. Snyder JT, Tzermiadianos MN, Ghanayem AJ, et al. Effect of uncovertebral joint excision on the motion response of the cervical spine after total disc replacement. Spine (Phila Pa 1976) 2007;32:2965-9.

21. Peng CW, Quirno M, Bendo JA, Spivak JM, Goldstein JA. Effect of intervertebral disc height on postoperative motion and clinical outcomes after Prodisc-C cervical disc replacement. Spine J 2009;9:551-5. 